\title{
Matching-adjusted indirect treatment comparison of ribociclib and palbociclib in HR+, HER2- advanced breast cancer
}

This article was published in the following Dove Press journal: Cancer Management and Research

\section{Gabriel Tremblay' \\ David Chandiwana ${ }^{2}$ \\ Mike Dolph' \\ Jaclyn Hearnden' \\ Anna Forsythe' \\ Mauricio Monaco ${ }^{2}$}

'Purple Squirrel Economics, New York, NY, USA; ${ }^{2}$ Novartis Pharmaceutical

Corporation, East Hanover, NJ, USA
Correspondence: Gabriel Tremblay Purple Squirrel Economics, 4 Lexington Ave, Suite 15K, New York, NY, USA Tel + I 64666 I 5496

Email gabrieltremblay@pshta.com
Background: Ribociclib (RIBO) and palbociclib (PALBO), combined with letrozole (LET), have been evaluated as treatments for hormone receptor-positive, human epidermal growth factor receptor 2-negative advanced breast cancer in separate Phase III randomized controlled trials (RCTs), but not head-to-head. Population differences can lead to biased results by classical indirect treatment comparison (ITC). Matching-adjusted indirect comparison (MAIC) aims to correct these differences. We compared RIBO and PALBO in hormone receptor-positive/human epidermal growth factor receptor 2-negative advanced breast cancer using MAIC.

Methods: Patient-level data were available for RIBO (MONALEESA-2), while only published summary data were available for PALBO (PALOMA-2). Weights were assigned to MONALEESA-2 patient data such that mean baseline characteristics matched those reported for PALOMA-2; the resulting matched cohort was used in comparisons. Limited by the results reported in PALOMA-2, progression-free survival (PFS) was the primary comparison. Cox regression models were used to calculate adjusted hazard ratios (HRs) for PFS, before indirect treatment comparison (ITC) was performed with 95\% confidence intervals. An exploratory analysis was performed similarly for overall survival using earlier PALBO data (PALOMA-1). Grade 3/4 adverse events were also compared.

Results: Racial characteristics, prior chemotherapy setting, and the extent of metastasis were the most imbalanced baseline characteristics. The unadjusted PFS HRs were $0.556(0.429$, $0.721)$ for RIBO+LET versus LET alone and $0.580(0.460,0.720)$ for PALBO+LET versus LET alone. MAIC adjustment resulted in an HR of $0.524(0.406,0.676)$ for RIBO+LET versus LET. PFS ITC using unadjusted trial data produced an HR of $0.959(0.681,1.350)$ for RIBO versus PALBO, or $0.904(0.644,1.268)$ with MAIC. Unadjusted overall survival HR of RIBO versus PALBO was $0.918(0.492,1.710)$; while exploratory MAIC was $0.839(0.440,1.598)$. ITC of grade $3 / 4$ adverse events yielded a risk ratio of $0.806(0.604,1.076)$.

Conclusion: MAIC was performed for RIBO and PALBO in the absence of a head-to-head trial: though not statistically significant, the results favored RIBO.

Keywords: breast cancer, indirect treatment comparison, matching-adjusted indirect treatment comparison, ribociclib, palbociclib

\section{Introduction}

Breast cancer is the most prevalent cancer in women and is the second deadliest after lung cancer. An estimated 246,660 new cases of breast cancer were diagnosed in the USA in 2016 and an estimated 40,450 breast cancer deaths occurred. Approximately $12.4 \%$ of women will develop breast cancer over the course of their lifetime. ${ }^{1}$ While breast cancer is detected at an early stage $90 \%$ of the time, many cases will progress 
to advanced or metastatic disease. ${ }^{2,3}$ Once metastases are detected, the median survival rate is $18-24$ months and fewer than $5 \%$ of patients are expected to be alive and disease-free after 5 years. ${ }^{4}$ The most favorable prognosis is conferred to $74 \%$ of the patient population who have tumors that express hormonal receptors $(\mathrm{HR}+)$ and do not express human epidermal growth factor receptor 2 (HER2 [HER2-]). These tumors are more responsive to therapy than $\mathrm{HR}-$ tumors and less aggressive than HER2+ tumors. ${ }^{5}$

Postmenopausal women with HR+/HER2- advanced breast cancer (ABC) typically receive hormonal therapy (HT) as initial treatment. ${ }^{6}$ The agents used include selective estrogen receptor antagonists tamoxifen and fulvestrant and aromatase inhibitors: exemestane, letrozole, and anastrozole. ${ }^{7}$ Considering patients with advanced HR+ tumors, only $20 \%-40 \%$ respond to therapy initially and the majority will ultimately develop resistance. ${ }^{8,9}$ Subsequently, HT may be used in combination with targeted therapy. Therapies that target pathways involved in resistance can restore or increase sensitivity to $\mathrm{HT}^{6}{ }^{6}$ Everolimus and palbociclib (PALBO) are currently approved by the US Food and Drug Administration for the treatment for $\mathrm{HR}+\mathrm{HER} 2-\mathrm{ABC}$ in combination with aromatase inhibitors. In first- and second-line randomized controlled trials (RCTs), both agents have been shown to improve progression-free survival (PFS) compared with HT alone. ${ }^{10,11}$

Ribociclib (RIBO), a cyclin-dependent kinase (CDK) 4/6 inhibitor similar to PALBO, was evaluated in a Phase III clinical trial as first-line treatment for postmenopausal women with HR+/HER2-ABC. In the recent MONALEESA-2 trial, patients with HR+ HER2- ABC who received RIBO with letrozole (LET) had better PFS than those who received LET alone: median PFS was not reached in the RIBO arm at data cut-off whereas median PFS was 14.7 months in the placebo arm. ${ }^{12}$ Patients in the RIBO and LET group experienced a $44 \%$ improvement in the risk of progression compared with those who received LET alone. ${ }^{12}$

Head-to-head comparison is an important tool to demonstrate treatment value and to aid decision-making. Accounting for the time required to perform a randomized trial, new agents may become available before they are compared with the relevant alternatives. Indirect treatment comparison (ITC), the statistical comparison of separate trials with like comparator groups, can provide timely evidence of comparative effectiveness. Guidelines and reviews of the methodologies now support the use of ITC, which is increasingly common. ${ }^{13-15}$ However, there is an important consideration associated with this method: ITC compares non-randomized treatment groups. Classical ITC can, therefore, generate biased results when trials of variable design with different patient populations are compared. Recent refinements of the ITC methodology have focused on accounting for trial dissimilarities.

Matching-adjusted indirect comparison (MAIC) corrects for baseline differences in patient populations, allowing for indirect comparison with limited bias when patient level data are available for only 1 study. Where individual patient data are available, baseline characteristics can be adjusted and reweighted to match summary statistics for comparator population. The adjusted treatment outcomes may then be compared. This approach has provided strong comparative evidence in the absence of head-to-head studies in various disease settings. ${ }^{14,16-19}$ RIBO and PALBO are CDK4/6 inhibitors demonstrated to be effective in HR+/HER2- ABC and so their comparison is clinically and economically relevant. As their corresponding trials used the same comparator - LET - and individual patient data were available for RIBO, MAIC was considered an appropriate methodology to examine comparative effectiveness.

\section{Materials and methods}

A systematic literature search following the guidelines published by the Cochrane Collaboration ${ }^{22}$ and the UK's National Institute for Health and Clinical Excellence (NICE) ${ }^{13}$ was conducted and identified 2 relevant Phase III RCTs and 1 relevant Phase II RCT: MONALEESA-2 ${ }^{12}$, RIBO and LET (CLEE011A2301 Clinical Study Report, Novartis Data on File); PALOMA- $2^{20}$, PALBO and LET; and PALOMA- $1^{10}$, PALBO and LET. ${ }^{10}$

MONALEESA-2 and PALOMA-2 both reported PFS as the primary endpoint. MONALEESA-2 reported overall survival (OS) as the secondary endpoint at the most recent cut-off (January 4, 2017). PALOMA-2 did not report mature results for OS, whereas the Phase II PALOMA-1 trial did. Hence, this analysis compared PFS results from MONALEESA-2 and PALOMA-2 and OS results from MONALEESA-2 and PALOMA-1.

\section{ITC and MAIC statistical methods}

To ensure the comparability of the trials, transitivity assumptions were tested according to the NICE Decision Support Unit (DSU) Technical Support Document 18 using a Population Average Treatment Effect (PATE) test. ${ }^{13}$

Classical frequentist ITC was performed using the Bucher $(1997)^{23}$ method with 95\% confidence intervals (CIs). Treatment with LET and placebo was used as the common comparator to evaluate the efficacy of RIBO and LET versus PALBO and LET. 
The adjusted baseline characteristics, selected based on feasibility and availability, were: age, race, region, Eastern Cooperative Oncology Group (ECOG) performance status, disease stage at diagnosis, disease-free interval (binary variable $<12$ months, i.e., de novo), current extent of disease using metastatic sites (visceral versus non-visceral binary variable), number of metastatic sites, and chemotherapy setting at baseline. Variable matching for PFS was performed: as patient level data were available for only the MONALEESA-2 trial, these data were adjusted and reweighted to match PALOMA-2 statistical data. First, the MONALEESA-2 trial population was modified to align its inclusion/exclusion criteria with the PALOMA-2 population. Some patients in the RIBO total intention-to-treat (ITT) dataset were excluded from this analysis based on PALOMA-2 exclusion criteria. In the second step of the MAIC analysis, the RIBO population data were reweighted such that the means/percentages of patient characteristics common to both datasets matched comparator data.

The weights were created by performing a logistic regression on the patient-level RIBO data that included an extra observation representing the comparator's data (i.e., a patient to whom the mean/percentage summarized values for the comparator's patient characteristics were attributed). The predicted values (or propensity score) that resulted from the logistic regression were used to weight the RIBO trial data (i.e., adjusted hazard ratios (HRs) were calculated using weighted Cox regression models).

Matching variables for OS using PALOMA-1 followed, although PALOMA-1 was a Phase II study and had slightly different baseline characteristics than PALOMA-2. The number of baseline characteristics reported in the publication was limited and matching could only be performed using a small number of variables. The following variables were available for matching OS in PALOMA-1 versus MONALEESA-2: median age, ECOG. Considering the matching limitations and the low number of OS events that have occurred to date in MONALEESA-2, OS is presented as an exploratory analysis.

Matching-adjusted ITC was performed according to NICE DSU guidelines. ${ }^{13}$ Analyses were conducted using Stata (Version 13.1; StataCorp LP, College Station, TX, USA). Direct comparison of HRs for RIBO and PALBO was conducted and CIs were measured on a log scale.

\section{Results}

\section{Design of the compared studies}

The designs of MONALEESA-2 and PALOMA-2 are described in Table 1.
MONALEESA- 2 and PALOMA-2 had different followup periods ( $\sim 28$ versus 23 months). However, the length of the follow-up period is unlikely to affect time-to-event endpoints, such as the HRs for PFS and OS, and was, therefore, not deemed to be a significant transitivity issue. The inclusion criteria for MONALEESA-2 and PALOMA-2/PALOMA-1 were deemed similar and the dosage of LET was identical. However, different stratification variables were used. MONALEESA-2 trial population was stratified according to the presence of lung and/or liver metastasis, while PALOMA-2 and PALOMA-1 populations were stratified by disease site and disease-free interval.

\section{Patient characteristics}

The designs of the MONALEESA-2 and PALOMA-2/ PALOMA-1 trials were similar and were, therefore, considered suitable for comparison. Of the MONALEESA-2 ITT population, 334 patients were treated with RIBO and LET and 334 patients were treated with placebo and LET. In the PALOMA-2 trial, 444 patients were treated with PALBO and LET and 222 were assigned to the placebo and LET group. In the PALOMA-1 trial, 84 patients were treated with PALBO and LET and 81 were assigned to the LET group. Patient baseline characteristics are presented in Table 2 .

Site of metastasis, adjuvant chemotherapy, patient age, and primary tumor size are strong prognostic factors in metastatic breast cancer. ${ }^{21}$ As there was limited deviation in the PATE test, it was concluded that the data were robust enough to perform both an ITC (unmatched) and an MAIC with very little transitivity concern.

\section{PFS}

Patient characteristics common to both populations were matched, and the RIBO population was adjusted. Table 3 presents the levels of baseline characteristics (variables) in each population. The MONALEESA-2 population characteristics are also presented after adjustment to match PALOMA-2.

Median PFS was relatively consistent for the LET and placebo groups, with limited deviation from transitivity that would be potentially corrected by ITC and matching. Compared with LET and placebo, the unadjusted PFS HRs were $0.556(0.429 ; 0.721)$ for RIBO and LET and $0.580(0.460 ; 0.720)$ for PALBO and LET. MAIC with the PALOMA-2 population produced a PFS HR of 0.524 $(0.407 ; 0.676)$ for RIBO and placebo. The unadjusted HR for RIBO versus PALBO was $0.959(0.681 ; 1.350)$ while MAIC produced an HR of $0.904(0.644 ; 1.268)$. Figure 1 depicts these results. 
Table I Comparison of MONALEESA-2, and PALOMA-I and -2

\begin{tabular}{|c|c|c|c|}
\hline & MONALEESA-2 ${ }^{12}$ & PALOMA-2 ${ }^{20}$ & PALOMA-I ${ }^{10}$ \\
\hline Agent & Ribociclib (Novartis, Basel, Switzerland) & $\begin{array}{l}\text { Palbociclib (Pfizer, New York, NY, } \\
\text { USA) }\end{array}$ & $\begin{array}{l}\text { Palbociclib (Pfizer, New York, NY, } \\
\text { USA) }\end{array}$ \\
\hline Study design & Allocation: randomized masking: double-blind & $\begin{array}{l}\text { Allocation: randomized masking: } \\
\text { double-blind }\end{array}$ & $\begin{array}{l}\text { Allocation: randomized masking: open } \\
\text { label }\end{array}$ \\
\hline Inclusion criteria & $\begin{array}{l}\text { Postmenopausal women with localized } \\
\text { recurrent or metastatic cancer: ER+, HER2-, } \\
\text { no prior systemic therapy for advanced } \\
\text { disease, measurable disease per RECIST } \\
\text { I.I or one predominantly lytic bone lesion, } \\
\text { ECOG 0-I }\end{array}$ & $\begin{array}{l}\text { Postmenopausal women with } \\
\text { localized recurrent or metastatic } \\
\text { cancer: ER+, no prior systemic } \\
\text { therapy for ER+ cancer, measurable } \\
\text { disease per RECIST or bone only } \\
\text { disease, ECOG 0-2, adequate organ/ } \\
\text { marrow function }\end{array}$ & $\begin{array}{l}\text { Postmenopausal women with localized } \\
\text { recurrent or metastatic cancer: ER+, } \\
\text { HER2-, no previous treatment for } \\
\text { advanced disease, measurable disease } \\
\text { per RECIST or bone only disease, } \\
\text { ECOG 0-I, adequate organ/marrow } \\
\text { function }\end{array}$ \\
\hline Exclusion criteria & $\begin{array}{l}\text { Prior treatment with a CDK inhibitor, } \\
\text { prior systemic therapy, concurrent use of } \\
\text { another anti-cancer therapy, concurrent } \\
\text { malignancy or malignancy within } 3 \text { years } \\
\text { of randomization, active cardiac disease or } \\
\text { history of dysfunction, systolic blood pressure } \\
>160 \text { or }<90 \mathrm{mmHg} \text {, patients receiving certain } \\
\text { medications that cannot be discontinued }\end{array}$ & $\begin{array}{l}\text { HER2+, patients at risk of life- } \\
\text { threatening complications in the } \\
\text { short term, known uncontrolled } \\
\text { or symptomatic CNS metastases, } \\
\text { prior treatment with letrozole/ } \\
\text { anastrozole with DFI } \leq 12 \text { months } \\
\text { from completion of treatment, prior } \\
\text { treatment with a CDK inhibitor }\end{array}$ & $\begin{array}{l}\text { Previous treatment for advanced } \\
\text { disease, prior treatment with letrozole } \\
\text { as either neoadjuvant or adjuvant } \\
\text { treatment within the } 12 \text { months before } \\
\text { study entry, any previous treatment } \\
\text { for advanced breast cancer, brain } \\
\text { metastasis, or previous treatment with } \\
\text { a CDK inhibitor }\end{array}$ \\
\hline Enrollment & 668 & 650 (estimated) & 165 \\
\hline Experimental arm & $\begin{array}{l}600 \mathrm{mg} \text { LEEO I I orally ( } 3 \text { weeks on/ I week } \\
\text { off) in combination with once daily } 2.5 \mathrm{mg} \\
\text { letrozole }\end{array}$ & $\begin{array}{l}\text { I } 25 \mathrm{mg} \text { PD- } 033299 \text { I orally ( } 3 \text { weeks } \\
\text { on/I week off) in combination with } \\
\text { once daily } 2.5 \mathrm{mg} \text { letrozole }\end{array}$ & $\begin{array}{l}\text { I } 25 \mathrm{mg} \text { PD-033299I orally ( } 3 \text { weeks } \\
\text { on/I week off) in combination with } \\
\text { once daily } 2.5 \mathrm{mg} \text { letrozole }\end{array}$ \\
\hline Comparator arm & $\begin{array}{l}\text { Placebo orally ( } 3 \text { weeks on/l week off) in } \\
\text { combination with once daily } 2.5 \mathrm{mg} \text { letrozole }\end{array}$ & $\begin{array}{l}\text { Placebo orally ( } 3 \text { weeks on/I week } \\
\text { off) in combination with once daily } \\
2.5 \mathrm{mg} \text { letrozole }\end{array}$ & $\begin{array}{l}\text { Once daily } 2.5 \mathrm{mg} \text { letrozole tablets on } \\
\text { a continuous regime }\end{array}$ \\
\hline $\begin{array}{l}\text { Primary outcome } \\
\text { measure }\end{array}$ & PFS, time frame: up to 20 months & $\begin{array}{l}\text { PFS, time frame: baseline up to } \\
2.5 \text { years }\end{array}$ & $\begin{array}{l}\text { PFS, time frame: assessed up to } \\
41 \text { months }\end{array}$ \\
\hline $\begin{array}{l}\text { Secondary outcome } \\
\text { measures }\end{array}$ & OS: up to 65 months & OS: up to 6 years & OS: up to 41 months (median) \\
\hline
\end{tabular}

Notes: Outcome measures irrelevant to this study are not listed.

Abbreviations: CDK, cyclin-dependent kinase; DFI, disease-free interval; ECOG, European Cooperative Oncology Group (performance status); ER+, estrogen receptorpositive; HER2-, human epidermal growth factor 2-negative; HER2+, human epidermal growth factor 2-positive; OS, overall survival; PFS, progression-free survival; RECIST, Response Evaluation Criteria In Solid Tumors.

Table 2 Patient characteristics

\begin{tabular}{|c|c|c|c|c|c|c|}
\hline \multirow[t]{2}{*}{ Patient characteristics } & \multicolumn{2}{|c|}{ Ribociclib (MONALEESA-2) 12} & \multicolumn{2}{|c|}{ Palbociclib (PALOMA-2) ${ }^{20}$} & \multicolumn{2}{|c|}{ Palbociclib (PALOMA-I) ${ }^{10}$} \\
\hline & RIBO+LET & PBO+LET & PALBO+LET & PBO+LET & PALBO+LET & LET \\
\hline Age criteria & \multicolumn{2}{|l|}{$\geq 18$} & \multicolumn{2}{|c|}{ NR (postmenopausal) } & \multicolumn{2}{|c|}{$\geq 18$ (postmenopausal) } \\
\hline Median age & 62 & 63 & 62 & 61 & 63 & 64 \\
\hline Age: $\geq 65$ & $45 \%$ & $43 \%$ & $41 \%$ & $37 \%$ & NR & NR \\
\hline \multicolumn{7}{|l|}{ Race } \\
\hline White & $80.5 \%$ & $83.8 \%$ & $77.5 \%$ & $77.5 \%$ & NR & NR \\
\hline Black & $3.0 \%$ & $2.1 \%$ & $1.8 \%$ & $1.4 \%$ & NR & NR \\
\hline Asian & $8.4 \%$ & $6.9 \%$ & $14.6 \%$ & $13.5 \%$ & NR & NR \\
\hline Native American & $0.3 \%$ & $0 \%$ & NR & NR & NR & NR \\
\hline Pacific Islander & $0.3 \%$ & $0 \%$ & NR & NR & NR & NR \\
\hline Other & $3.6 \%$ & $2.4 \%$ & $6.1 \%$ & $7.7 \%$ & NR & NR \\
\hline Unknown & $3.9 \%$ & $4.8 \%$ & NR & NR & NR & NR \\
\hline \multicolumn{7}{|l|}{ Region } \\
\hline North America & $32.3 \%$ & $36.2 \%$ & $37.8 \%$ & $44.6 \%$ & NR & NR \\
\hline Non-North America & $67.7 \%$ & $63.8 \%$ & $62.2 \%$ & $55.4 \%$ & NR & NR \\
\hline \multicolumn{7}{|l|}{ ECOG: } \\
\hline 0 & $61.4 \%$ & $60.5 \%$ & $57.9 \%$ & $45.9 \%$ & $55 \%$ & $56 \%$ \\
\hline I & $38.6 \%$ & $39.5 \%$ & $40.1 \%$ & $52.7 \%$ & $45 \%$ & $44 \%$ \\
\hline 2 & $0 \%$ & $0 \%$ & $2.0 \%$ & $1.4 \%$ & $0 \%$ & $0 \%$ \\
\hline 3 & $0 \%$ & $0 \%$ & $0 \%$ & $0 \%$ & $0 \%$ & $0 \%$ \\
\hline 4 & $0 \%$ & $0 \%$ & $0 \%$ & $0 \%$ & $0 \%$ & $0 \%$ \\
\hline
\end{tabular}


Table 2 (Continued)

\begin{tabular}{|c|c|c|c|c|c|c|}
\hline \multirow[t]{2}{*}{ Patient characteristics } & \multicolumn{2}{|c|}{ Ribociclib (MONALEESA-2) ${ }^{12}$} & \multicolumn{2}{|c|}{ Palbociclib (PALOMA-2) ${ }^{20}$} & \multicolumn{2}{|c|}{ Palbociclib (PALOMA-I) ${ }^{10}$} \\
\hline & RIBO+LET & PBO+LET & PALBO+LET & PBO+LET & PALBO+LET & LET \\
\hline \multicolumn{7}{|l|}{ Primary site of cancer: } \\
\hline Breast & $100 \%$ & $100 \%$ & $100 \%$ & $100 \%$ & $100 \%$ & $100 \%$ \\
\hline \multicolumn{7}{|l|}{ Histological grade: } \\
\hline Well differentiated & $9.0 \%$ & $10.5 \%$ & NR & NR & NR & NR \\
\hline Moderately differentiated & $42.8 \%$ & $38.3 \%$ & $N R$ & NR & NR & NR \\
\hline Poorly differentiated & $17.7 \%$ & $22.5 \%$ & $N R$ & NR & NR & NR \\
\hline Undifferentiated & $0.9 \%$ & $1.5 \%$ & NR & NR & NR & NR \\
\hline Unknown & $29.6 \%$ & $26.6 \%$ & NR & NR & NR & NR \\
\hline Missing & $0 \%$ & $0.6 \%$ & NR & NR & NR & NR \\
\hline \multicolumn{7}{|l|}{ Stage at initial diagnosis: } \\
\hline 0 & $2.1 \%$ & $1.8 \%$ & $0 \%$ & $0 \%$ & NR & NR \\
\hline 1 & $16.5 \%$ & $14.4 \%$ & $11.5 \%$ & $13.5 \%$ & NR & NR \\
\hline II & $29.3 \%$ & $32.0 \%$ & $30.9 \%$ & $30.6 \%$ & NR & NR \\
\hline III & $17.4 \%$ & $18.6 \%$ & $16.2 \%$ & $17.6 \%$ & NR & NR \\
\hline IV & $34.4 \%$ & $32.3 \%$ & $31.1 \%$ & $32.4 \%$ & NR & NR \\
\hline Unknown/missing & $0.3 \%$ & $0.9 \%$ & $10.4 \%$ & $5.9 \%$ & NR & NR \\
\hline \multicolumn{7}{|l|}{ Stage at study entry: } \\
\hline III & $0.3 \%$ & $0.9 \%$ & NR & NR & $2 \%$ & $1 \%$ \\
\hline IV & $99.7 \%$ & $99.1 \%$ & NR & NR & $98 \%$ & $99 \%$ \\
\hline \multicolumn{7}{|c|}{ Time since initial diagnosis of primary site } \\
\hline (median months) & 58.1 & 52.1 & NR & NR & NR & NR \\
\hline \multicolumn{7}{|l|}{ Disease-free interval: } \\
\hline De novo & $34.1 \%$ & $33.8 \%$ & $37.6 \%$ & $36.5 \%$ & $52 \%$ & $46 \%$ \\
\hline Non-de novo & $65.9 \%$ & $66.2 \%$ & $62.4 \%$ & $63.5 \%$ & $48 \%$ & $54 \%$ \\
\hline \multicolumn{7}{|l|}{ Types of lesions at baseline: } \\
\hline Target only & $9.6 \%$ & $8.4 \%$ & NR & NR & NR & NR \\
\hline Non-target only & $23.1 \%$ & $26.3 \%$ & NR & NR & NR & NR \\
\hline Both target and non-target & $67.1 \%$ & $65.0 \%$ & NR & NR & NR & NR \\
\hline Unknown & $0.3 \%$ & $0.3 \%$ & NR & NR & NR & NR \\
\hline \multicolumn{7}{|l|}{ HER2 receptor status: } \\
\hline Positive & $0.3 \%$ & $0.3 \%$ & $0 \%$ & $0 \%$ & $0 \%$ & $0 \%$ \\
\hline Negative & $99.7 \%$ & $99.7 \%$ & $100 \%$ & $100 \%$ & $100 \%$ & $100 \%$ \\
\hline \multicolumn{7}{|l|}{ Estrogen receptor status } \\
\hline Positive & $99.4 \%$ & $99.7 \%$ & $100 \%$ & $100 \%$ & $100 \%$ & $100 \%$ \\
\hline Negative & $0.6 \%$ & $0.3 \%$ & $0 \%$ & $0 \%$ & $0 \%$ & $0 \%$ \\
\hline \multicolumn{7}{|l|}{ Progesterone receptor status } \\
\hline Positive & $81.1 \%$ & $83.2 \%$ & NR & NR & NR & NR \\
\hline Negative & $16.5 \%$ & $14.7 \%$ & NR & NR & NR & NR \\
\hline Unknown & $2.4 \%$ & $2.1 \%$ & NR & NR & NR & NR \\
\hline \multicolumn{7}{|c|}{ Estrogen and/or progesterone receptor } \\
\hline status & $100 \%$ & $100 \%$ & $100 \%$ & $100 \%$ & $100 \%$ & $100 \%$ \\
\hline \multicolumn{7}{|l|}{ At least one positive } \\
\hline Current extent of disease (me & & & & & & \\
\hline sites) & $2.4 \%$ & $3.3 \%$ & NR & NR & NR & NR \\
\hline Breast & $0 \%$ & $0.6 \%$ & NR & NR & NR & NR \\
\hline Bone marrow & $73.7 \%$ & $73.1 \%$ & $N R$ & NR & $20 \%$ & $15 \% \%$ \\
\hline Bone & $59.0 \%$ & $58.7 \%$ & $48.2 \%$ & $49.5 \%$ & $44 \%$ & $53 \%$ \\
\hline Visceral & $4.5 \%$ & $3.0 \%$ & NR & NR & NR & NR \\
\hline Skin & $39.8 \%$ & $36.8 \%$ & NR & NR & NR & NR \\
\hline Lymph nodes & $6.0 \%$ & $3.0 \%$ & NR & NR & NR & NR \\
\hline Others & $0.6 \%$ & $0.3 \%$ & $N R$ & NR & NR & NR \\
\hline None & NR & NR & $51.8 \%$ & $50.5 \%$ & $36 \%$ & $32 \%$ \\
\hline Total non-visceral & & & & & & \\
\hline Number of metastatic sites inv & & & & & & \\
\hline 0 & $0.6 \%$ & $0.3 \%$ & $N R$ & NR & NR & NR \\
\hline I & $29.9 \%$ & $35.0 \%$ & $31.1 \%$ & $29.7 \%$ & NR & NR \\
\hline 2 & $35.3 \%$ & $30.8 \%$ & $26.4 \%$ & $23.4 \%$ & NR & NR \\
\hline$>2$ & $34.2 \%$ & $33.9 \%$ & $42.5 \%$ & $46.9 \%$ & NR & NR \\
\hline
\end{tabular}

Abbreviations: ECOG, European Cooperative Oncology Group; HER2, human epidermal growth factor receptor 2; LET, letrozole; NR, not reported; PALBO, palbociclib; RIBO, ribociclib. 
Table 3 Patient characteristics before and after adjustment (in "levels")

\begin{tabular}{llll}
\hline Variable & $\begin{array}{l}\text { Level in MONALEESA-2 } \\
\text { before matching }\end{array}$ & Level in PALOMA-2 & $\begin{array}{l}\text { Level in MONALEESA-2 } \\
\text { after matching }\end{array}$ \\
\hline Age & 61.594 & 61.667 & 61.667 \\
Age group: $\geq 65$ & 0.441 & 0.397 & 0.397 \\
Race: White & 0.822 & 0.775 & 0.775 \\
$\quad$ Asian & 0.078 & 0.142 & 0.142 \\
$\quad$ Black & 0.026 & 0.017 & 0.017 \\
Region: North America & 0.343 & 0.401 & 0.401 \\
ECOG I & 0.392 & 0.479 & 0.479 \\
Prior chemo setting: adjuvant & 0.379 & 0.404 & 0.404 \\
Prior chemo setting: neoadjuvant & 0.100 & 0.129 & 0.129 \\
Prior hormonal setting: adjuvant & 0.518 & 0.563 & 0.563 \\
Stage 3+ at diagnosis & 0.527 & 0.529 & 0.529 \\
Metastatic sites (0-2) & 0.659 & 0.560 & 0.560 \\
Disease-free interval (de novo) & 0.370 & 0.372 & 0.372 \\
Visceral metastases & 0.591 & 0.486 & 0.486 \\
\hline
\end{tabular}

Notes: Differences of $\geq 10 \%$ are highlighted in gray.

Abbreviations: ECOG, European Cooperative Oncology Group; chemo, chemotherapy.

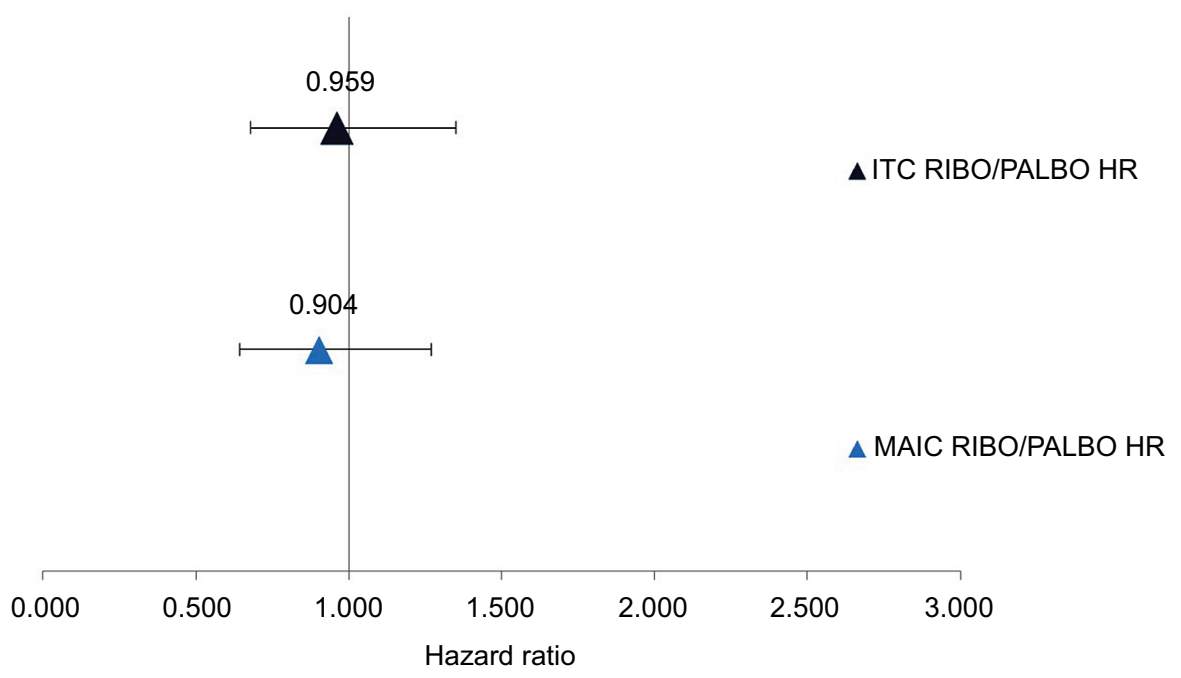

Figure I Progression-free survival for RIBO versus PALBO with and without matching adjustment.

Notes: $\mathrm{HR}<\mathrm{I}$ favors RIBO, $>$ I favors PALBO.

Abbreviations: HR, hazard ratio; ITC, indirect treatment comparison; MAIC, matching-adjusted indirect treatment comparison; PALBO, palbociclib; RIBO, ribociclib.

Regarding the statistical fitting of the matching, the estimate had a relatively small $\mathrm{R}$-square value for this type of regression: a pseudo R-square of 0.0251 (prob $>\chi^{2}=1$ ). Akaike information criterion (AIC) and Bayesian information criterion (BIC) statistics are valuable when comparing models. In this case, the AIC and BIC were 44.58 and 111.78 respectively, which indicates a moderate fit. The relatively large number of matching variables explains the difference in AIC and BIC, which could suggest overmatching. The MONALEESA-2 population was reduced by about $30 \%$ in each arm to fit the PALOMA-2. Compared with the ITT population, the effective sample size was $66 \%$ for RIBO and $71 \%$ for placebo (postexclusion sample sizes were $68 \%$ and $73 \%$, respectively), indicating moderate fit.

\section{OS}

Exploratory unadjusted and adjusted comparisons of OS were performed. As OS data from PALOMA-2 were unavailable, data for PALBO were obtained from the Phase II PALOMA-1 trial. Compared with LET and placebo, the unadjusted OS HRs were $0.746(0.517 ; 1.078)$ for RIBO and LET and $0.813(0.492 ; 1.345)$ for PALBO and LET. MAIC with the PALOMA-1 population produced an OS HR of $0.682(0.456 ; 1.021)$ for RIBO and placebo. The unadjusted HR for RIBO versus PALBO was 0.918 (0.492; 1.710) while MAIC produced an HR of 0.839 ( 0.440 ; 1.598). The HR results of this analysis are presented in Figure 2. 


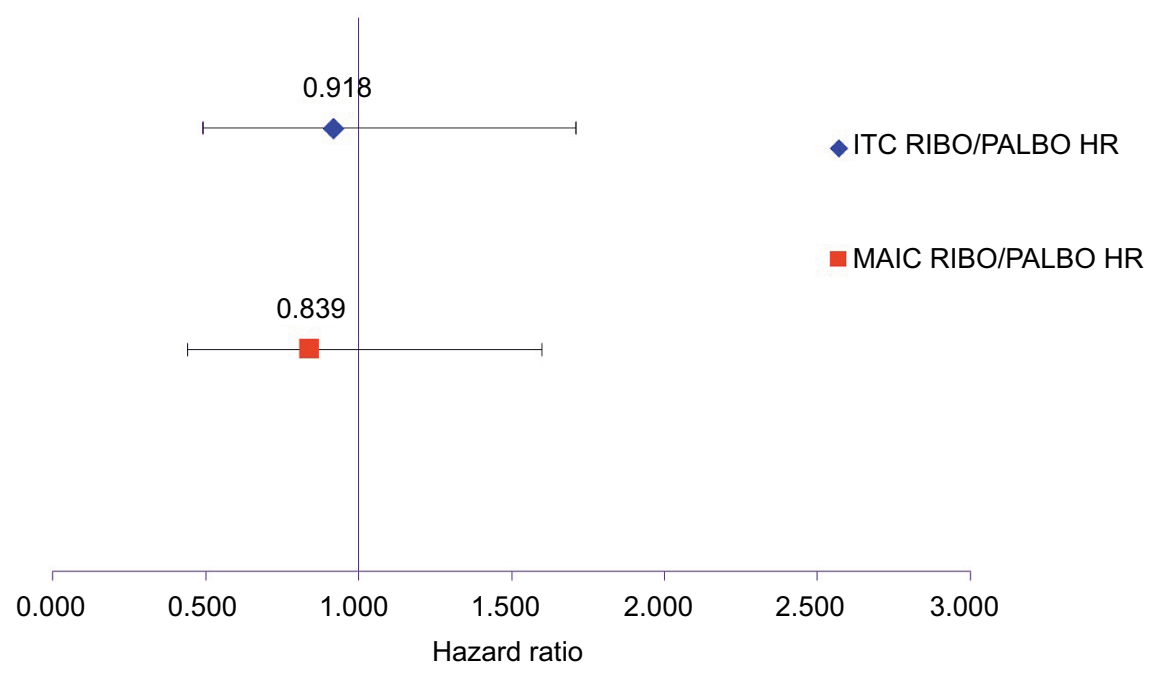

Figure 2 Overall survival for RIBO versus PALBO with and without matching adjustment.

Notes: HR $<$ I favors RIBO, $>$ I favors PALBO.

Abbreviations: HR, hazard ratio; ITC, indirect treatment comparison; MAIC, matching-adjusted indirect treatment comparison; PALBO, palbociclib; RIBO, ribociclib.

\section{Grade 3/4 adverse events}

The ITC of grade $3 / 4$ adverse events yielded a risk ratio of $0.806(0.604 ; 1.076$; Table 4), indicating a trend of fewer severe adverse events with RIBO.

\section{Discussion}

An analysis was performed to determine the efficacy of RIBO compared with PALBO for the treatment of $\mathrm{HR+l}$ HER2 - ABC. This analysis compared PFS and OS in Phase II/III trials of RIBO or PALBO and LET treatment with and without matching adjustment.

In MONALEESA-2, RIBO plus LET was shown to improve PFS versus LET alone. ${ }^{12}$ The MONALEESA-2 PFS HR for RIBO and LET treatment versus LET alone decreased following matching to the PALOMA-2 trial population data: an HR of $0.556(0.429 ; 0.721)$ became 0.524 (0.406; 0.676). RIBO, therefore, demonstrated improved results in the PALOMA- 2 context compared with the MONALEESA-2 context. Upon comparison by classical ITC, RIBO and PALBO were ultimately similar: an HR of 0.959 (0.681; 1.35) for PFS. However, following MAIC, the HR for RIBO compared with PALBO was $0.904(0.644 ; 1.268)$. The unadjusted OS HR of $0.918(0.517 ; 1.078)$ using PALOMA-1 improved to $0.839(0.440 ; 1.598)$ upon exploratory MAIC. Considering comparable populations, RIBO fared better than PALBO. Although not statistically significant, these important results demonstrate that if RIBO and PALBO were compared directly, RIBO may have proved the superior agent.

When assessing therapies in breast cancer, and other diseases with relatively lengthy courses, PFS is a highly relevant outcome. PFS is measured before OS becomes
Table 4 Indirect treatment comparison of grade 3/4 adverse events

\begin{tabular}{llll}
\hline & Treatment & Control & Risk ratio (95\% Cl) \\
\hline Grade 3-4 adverse events & & \\
Direct & Ribociclib & Placebo & $2.509(2.130-2.955)$ \\
comparison & Palbociclib & & 3.1 II $(2.452-3.947)$ \\
ITC & Ribociclib & Palbociclib & $0.806(0.604-1.076)$ \\
\hline
\end{tabular}

Abbreviation: ITC, indirect treatment comparison.

apparent and provides an indication of a disease's behavior during treatment. PFS has implications for OS and may serve as a proxy for OS in the absence of complete data. MONALEESA-2 is ongoing and the limited number of OS events that have occurred to date would not be expected to accurately represent the total population. No data have been reported for PALOMA-2 OS. Both trials used PFS as the primary outcome measure and, as such, it is the most robust point of comparison for RIBO and PALBO.

In MAIC, patients in 1 population are selected according to their baseline characteristics to replicate a comparator population; this process can be said to break randomization. The implicated variables were not necessarily pre-specified as randomization variables. Simultaneously, a selection bias may result when some baseline characteristics are omitted due to availability. Of additional concern, sample size is reduced during MAIC, which can create a multiplicity bias. Finally, the addition of many variables may result in over-adjustment. Although in this analysis, the statistical fitting and testing performed indicated a moderate fit and, therefore, a limited likelihood of bias, classical and MAIC results proved relatively similar, indicating strong convergence in our findings. 
The indirect comparison of RIBO with PALBO, with matching adjustment, predicted how these agents would perform under the same conditions. In our analysis, MAIC suggested 1 of 2 agents that appeared similar by ITC could be the superior choice. We demonstrate, in the absence of a head-to-head clinical trial, that RIBO could compete with or improve upon PALBO results.

\section{Acknowledgments}

Parts of this study were featured in a poster presented at the 2017 European Society for Medical Oncology Congress; the abstract is published and is available in the Annals of Oncology (2017) 28 (suppl_5): v74-v108. 10.1093/annonc/ mdx365. This study was sponsored by Novartis.

\section{Author contributions}

GT made substantial contributions to the conception and design, analyzed and interpreted the data, and critically revised the article. MD acquired and analyzed the data, and contributed to the drafting and revision of the manuscript. DC, AF, and MM made substantial contributions to conception and design, and critically revised the article for important intellectual content. JH contributed to data interpretation and drafting and revising the article. All authors agree to be accountable for all aspects of the work.

\section{Disclosure}

DC and MM are employees of Novartis. The authors report no other conflicts of interest in this work.

\section{References}

1. Siegel RL, Miller KD, Jemal A. Cancer statistics, 2016. CA Cancer J Clin. 2016;66(1):7-30.

2. Early Breast Cancer Trialists' Collaborative G. Effects of chemotherapy and hormonal therapy for early breast cancer on recurrence and 15-year survival: an overview of the randomised trials. Lancet. 2005;365(9472):1687-1717.

3. Clemons M, Danson S, Hamilton T, Goss P. Locoregionally recurrent breast cancer: incidence, risk factors and survival. Cancer Treat Rev. 2001;27(2):67-82.

4. Martino M, Ballestrero A, Zambelli A, et al. Long-term survival in patients with metastatic breast cancer receiving intensified chemotherapy and stem cell rescue: data from the Italian registry. Bone Marrow Transplant. 2013;48(3):414-418.

5. Breast Cancer Facts \& Figures 2015-2016. In: Society AC, editor. Atlanta, GA: American Cancer Society, Inc.; 2015. Available from: https://www.cancer.org/research/cancer-facts-statistics/breast-cancerfacts-figures.html. Accessed March 28, 2018.
6. Reinert T, Barrios CH. Optimal management of hormone receptor positive metastatic breast cancer in 2016. Ther Adv Med Oncol. 2015;7(6):304-320.

7. Breast Cancer Treatment $\left(P D Q^{\circledR}\right)-$ Health Professional Version. Bethesda, MD: National Cancer Institute; 2017.

8. Johnston SR. New strategies in estrogen receptor-positive breast cancer. Clin Cancer Res. 2010;16(7):1979-1987.

9. Gonzalez-Angulo AM, Morales-Vasquez F, Hortobagyi GN. Overview of resistance to systemic therapy in patients with breast cancer. $A d v \operatorname{Exp}$ Med Biol. 2007;608:1-22.

10. Finn RS, Crown JP, Lang I, et al. The cyclin-dependent kinase $4 / 6$ inhibitor palbociclib in combination with letrozole versus letrozole alone as first-line treatment of oestrogen receptor-positive, HER2-negative, advanced breast cancer (PALOMA-1/TRIO-18): a randomised phase 2 study. Lancet Oncol. 2015;16(1):25-35.

11. Baselga J, Campone M, Piccart M, et al. Everolimus in postmenopausal hormone-receptor-positive advanced breast cancer. $N$ Engl J Med. 2012;366(6):520-529.

12. Hortobagyi GN, Stemmer SM, Burris HA, et al. Ribociclib as firstline therapy for hr-positive, advanced breast cancer. $N$ Engl $J$ Med. 2016;375(18):1738-1748.

13. Phillipp D, Ades, AE, Dias, S, Palmer, S, Abrams, KR, Welton, NJ NICE DSU technical support document 18: methods for populationadjusted indirect comparisons in submissions to NICE. In: Unit DS, editor. Sheffield 2016.

14. Signorovitch JE, Sikirica V, Erder MH, et al. Matching-adjusted indirect comparisons: a new tool for timely comparative effectiveness research. Value Health. 2012;15(6):940-947.

15. Sutton A, Ades AE, Cooper N, Abrams K. Use of indirect and mixed treatment comparisons for technology assessment. Pharmacoeconomics. 2008;26(9):753-767.

16. Tremblay G, Livings C, Crowe L, Kapetanakis V, Briggs A. Determination of the most appropriate method for extrapolating overall survival data from a placebo-controlled clinical trial of lenvatinib for progressive, radioiodine-refractory differentiated thyroid cancer. Clinicoecon Outcomes Res. 2016;8:323-333.

17. Signorovitch J, Swallow E, Kantor E, et al. Everolimus and sunitinib for advanced pancreatic neuroendocrine tumors: a matching-adjusted indirect comparison. Exp Hematol Oncol. 2013;2(1):32.

18. Signorovitch JE, Betts KA, Reichmann WM, et al. One-year and longterm molecular response to nilotinib and dasatinib for newly diagnosed chronic myeloid leukemia: a matching-adjusted indirect comparison. Curr Med Res Opin. 2015;31(2):315-322.

19. Sikirica V, Findling RL, Signorovitch J, et al. Comparative efficacy of guanfacine extended release versus atomoxetine for the treatment of attention-deficit/hyperactivity disorder in children and adolescents: applying matching-adjusted indirect comparison methodology. CNS Drugs. 2013;27(11):943-953.

20. Finn RS, Martin M, Rugo HS, et al. Palbociclib and letrozole in advanced breast cancer. N Engl J Med. 2016;375(20):1925-1936.

21. Largillier R, Ferrero JM, Doyen J, et al. Prognostic factors in 1038 women with metastatic breast cancer. Ann Oncol. 2008;19(12): 2012-2019.

22. Higgins JPT, Green S (editors). Cochrane Handbook for Systematic Reviews of Interventions Version 5.1.0 [updated March 2011]. The Cochrane Collaboration, 2011. Available from http://handbook. cochrane.org. Accessed MArch 28, 2018

23. Bucher HC, Guyatt GH, Griffith LE, Walter SD. The results of direct and indirect treatment comparisons in meta-analysis of randomized controlled trials. J Clin Epidemiol. 1997;50(6):683-691. 
Cancer Management and Research

\section{Publish your work in this journal}

Cancer Management and Research is an international, peer-reviewed open access journal focusing on cancer research and the optimal use of preventative and integrated treatment interventions to achieve improved outcomes, enhanced survival and quality of life for the cancer patient.

The manuscript management system is completely online and includes

Submit your manuscript here: https://www.dovepress.com/cancer-management-and-research-journal

a very quick and fair peer-review system, which is all easy to use. Visit $\mathrm{http}: / / \mathrm{www}$.dovepress.com/testimonials.php to read real quotes from published authors. 